\title{
IMPLEMENTASI KNOWLEDGE MANAGEMENT DAN ANALISIS SWOT DI PERPUSTAKAAN SEKOLAH MENENGAH ATAS (SMA)
}

\section{Implementation of Knowledge Management and Swot Analysis in High School Libraries}

\author{
Yanthi Charolina ${ }^{1)^{*}}$ \\ 1) Program Studi Sistem Informasi, Universitas Bunda Mulia, Jakarta
}

Diterima 20 Maret 2020 / Dis etujui 27 Maret 2020

\begin{abstract}
The School Library must be able to understand the concepts of Knowledge Management and make a SWOT analysis. The purpose of this paper is to describe the implementation of knowledge management and SWOT analysis in the School Library. The method used by data collection is by observation / observation and using internet sources, study materials and scientific journals. The results of this paper found that to achieve the implementation of knowledge management and SWOT analysis, (1) the School Library is expected to: (a) Understand the concept of Knowledge Management (creation, recording and organization, dissemination, access and use, and continued with the re-creation of knowledge, and so on), (b) Become a partner for users, (c) Serve individuals or groups as members of the network, (d) Provide Knowledge Management facilities.
\end{abstract}

Keywords: Implementation of Knowledge Management, SWOT Analysis, High School Library

\begin{abstract}
ABSTRAK
Perpustakaan Sekolah harus mampu memahami konsep-konsep Knowledge Management dan membuat analisis SWOT. Tujuan penulisan ini adalah mendeskripsikan implementasi knowledge management dan analisis SWOT di Perpustakaan Sekolah. Metode yang digunakan dengan pengumpulan data dengan cara pengamatan / observasi dan menggunakan sumber internet, bahan matapelajaran dan karya tulis. Hasil penulisan ini menemukan bahwa untuk tercapainya implementasi knowledge management dan analisis SWOT, maka (1) Perpustakaan Sekolah diharapkan: (a) Memahami konsep Knowledge Management (penciptaan, perekaman dan organisasi, penyebaran, akses dan pengunaan, dan dilanjutkan dengan penciptaan kembali pengetahuan, dan seterusnya), (b) Menjadi mitra bagi pengguna, (c) Melayani individu atau kelompok sebagai anggota jaringan, (d) Menyediakan fasilitas Knowledge Management.
\end{abstract}

Kata kunci : Implementasi Knowledge Management, Analisis SWOT, Perpustakaan SMA

*Korespondensi Penulis :

E-mail: charolinayanthi756@gmail.com 


\section{PENDAHULUAN}

\section{Knowledge Management System}

(KMS) memainkan peranan penting dalam menciptakan, mendokumentasikan, menggolongkan dan menyebarkan pengetahuan tersebut diantara seluruh anggotanya. Sehingga perusahaan tidak akan kehilangan pengetahuan yang ada, bahkan dapat mengorganisir dan menfaatkannya dalam pembangunan inteligensi perusahaan.

Knowledge management juga bisa dikatakan sebuah proses menciptakan, membagikan, menggunakan, dan mengelola suatu pengetahuan dan informasi dari sebuah organisasi. Kehadiran KM dalam sebuah perusahaan membawa dampak yang signifikan untuk suksesnya sebuah perusahaan dalam menjalankan fungsinya. Hadagali dkk. (2012) menjelaskan bahwa KM membuat sebuah organisasi menjadi lebih produktif, lebih efektif dan lebih sukses.

Sebagai landasan hukum mengacu
pada Peraturan Pemerintah Republik
Indonesia Nomor 24 Tahun 2014 Tentang
Pelaksanaan Undang-Undang Nomor 43
Tahun 2007 Tentang Perpustakaan dalam penjelasannya pada bab IV pasal 9 bahwa sebuah perpustakaan khususnya perpustakaan sekolah disebut memenuhi standar nasional apabila perpustakaan tersebut memenuhi kriteria di antaranya, standar koleksi perpustakaan, standar sarana dan prasarana, standar pelayanan perpustakaan, standar tenaga perpustakaan, standar penyelenggaraan dan standar pengelolaan (Perpustakaan Nasional Republik Indonesia, 2014: 6). Dalam Undang-Undang Nomor 43 Tahun 2007 dijelaskan pada Bab III Pasal 11 bahwa Standar Nasional Perpustakaan terdiri atas standar koleksi perpustakaan, standar sarana dan prasarana, standar pelayanan perpustakaan, standar tenaga perpustakaan, standar penyelenggaraan, dan standar pengelolaan. Standar Nasional Perpustakaan sebagaimana dimaksud pada ayat (1) digunakan sebagai acuan penyelenggaraan, pengelolaan, dan pengembangan perpustakaan. Ketentuan lebih lanjut mengenai standar nasional perpustakaan sebagaimana dimaksud pada ayat (1) diatur dengan peraturan pemerintah (Presiden Republik Indonesia, 2007:8).

Hadirnya teknologi informai dan komunikasi telah mengubah paradigma perpustakaan dari sistem perpustakaan konvensional ke sistem perpustakaan berbasis TIK. Yooke Tjuparman S. Komaruddin dalam (Brophy, 2002: 5-11) menyatakan bahwa perubahan paradigma ini dipengaruhi oleh beberapa unsur yaitu hadirnya electronic paper, model penerbitan baru, toko buku online, e-commerce, televisi digital, lingkungan pembelajaran terpadu, universitas jarak jauh, mobile communications, print-on-demand dan the threat of the unknown. Teknologi merupakan hal yang kompleks dan pustakawan belum mengembangkan keterampilan untuk mengerti, memahami dan mengkreasi TIK. Artinya pustakawan belum siap menghadapi perpustakaan berbasis TIK. Perpustakaan masih merupakan barang mahal dan akan lebih mahal lagi, karena pustakawan belum mempunyai strategi manajemen pengetahuan yang tepat dan pustakawan belum berani menunjukkan kompetisinya. Hal ini juga dipengaruhi oleh organisasi penaung perpustakaan yang belum memberikan dukungan untuk kebutuhan operasional perpustakaan berbasis TIK khususnya pengadaan konten perpustakaan.

Perpustakaan Sekolah harus mampu memenuhi kebutuhan pengguna perpustakaan berbasis TIK dan pimpinan perpustakaan diharapkan mampu memahami bagaimana 
potensi dan skill yang dimiliki oleh stafnya, serta mampu membuat analisis SWOT terhadap perpustakaannya yang meliputi Strengthen (adanya kekuatan), Weakness (kelemahan), Opportunity (kesempatan atau peluang), Threats (adanya tantangan atau ancaman). Konsep analisis tersebut dipergunakan perpustakaan sekolah untuk mengetahui sejauh mana penyelenggaraan tugas dan fungsinya dalam melayani sekolah di bidang informasi, dokumentasi maupun ilmu pengetahuan sehingga seorang pimpinan perpustakaan mampu membuat strategi perubahan dalam lembaga perpustakaan. Kajian penulisan artikel ini fokus membahas Implementasi Knowledge Management dan Analisis SWOT di Perpustakaan Sekolah Menengah Atas. Penulisan artikel menggunakan metode pengumpulan data dengan cara observasi dan menggunakan sumber literatur, internet, bahan mata pelajaran dan jurnal ilmiah.

\section{TINJAUAN PUSTAKA}

\section{A. Knowle dge Management}

Manajemen pengetahuan (knowledge management) ialah suatu rangkaian kegiatan yang digunakan oleh organisasi atau perusahaan untuk mengidentifikasi, menciptakan, menjelaskan, dan mendistribusikan pengetahuan untuk digunakan kembali, diketahui, dan dipelajari di dalam organisasi. Kegiatan ini biasanya terkait dengan objektif organisasi dan ditujukan untuk mencapai suatu hasil tertentu seperti pengetahuan bersama, peningkatan kinerja, keunggulan kompetitif, atau tingkat inovasi yang lebih tinggi.

Konsep manajemen pengetahuan ini meliputi pengelolaan sumber daya manusia (SDM) dan teknologi informasi (TI) dalam tujuannya untuk mencapai organisasi perusahaan yang semakin baik sehingga mampu memenangkan persaingan bisnis. Perkembangan teknologi informasi memang memainkan peranan yang penting dalam konsep manajemen pengetahuan. Hampir semua aktivitas kehidupan manusia akan diwarnai oleh penguasaan teknologi informasi, sehingga jika berbicara mengenai manajemen pengetahuan tidak lepas dari pengelolaan.

Pada perkembangan ini menunjukan makin cepatnya perubahan dalam segala bidang kehidupan, akibat dari efek globalisasi serta perkembangan teknologi informasi yang sangat akseleratif. Kondisi ini jelas telah mengakibatkan perlunya cara-cara baru dalam menyikapi semua yang terjadi agar dapat tetap survive. Penekanan akan makin pentingnya kualitas sumber daya manusia (SDM) merupakan salah satu respon dalam menyikapi perubahan tersebut, dan ini tentu saja memerlukan upaya-upaya untuk meningkatkan dan mengembangkan SDM.

Knowledge Management menjadi tantangan tersendiri bagi sebuah Sekolah. Davenport dan Prusak (1998) menjelaskan bahwa proses KM diawali dari pengetahuan yaitu "knowledge is a fluid mix of framed experience, values, contextual information, and expert insight that provides a framework for evaluating and incorporating new experiences and information. It originates and is applied in the minds of knowers. In organizations, it often becomes embedded not only in documents or repositories but also in organizational routines, processes, practices and norms".

Pendapat di atas ditegaskan oleh Davenport dalam Abbas (2014) yang membagi pelaksanaan KM dalam 4 proses yaitu:

1. Menciptakan tempat penyimpanan pengetahuan. 
2. Memperbaiki akses pada pengetahuan.

3. Memajukan lingkungan pengetahuan.

4. Mengelola pengetahuan sebagai aset. Berdasarkan pendapat tersebut dapat dideskripsikan bahwa yang melakukan proses KM dalam sebuah Sekolah adalah Perpustakaan.

Perpustakaan Sekolah merupakan tempat penyimpanan pengetahuan yang menyediakan database buku, repository dan karya tulis. Database tersebut dikelola sebagai aset yang akan dilayankan kepada Bagian Perpustakaan dengan menyediakan akses yang berbasis TIK. Perpustakaan Sekolah sebagai lembaga informasi yang melayani kebutuhan seluruh siswa/siswi dalam melakukan proses KM. Manajemen Pengetahuan (knowledge management) berkaitan dengan upaya meningkatkan kinerja dan pembelajaran organisasi, melalui pemaksimalan penggunaan pengetahuan, memahami dan menerapkan pembelajaran.

Beberapa pengertian knowledge management antara lain:

1. Menurut Dave Owens, dkk dalam bahan kuliah MIP UGM (2014) bahwa knowledge management adalah:

a. Cara kerja dalam sebuah organisasi yang memastikan bahwa kemampuan intelektual organisasi dibagikan, dipelihara dan dilembagakan.

b. Proses pengelolaan dan pemanfaatan khazanah pengetahuan dalam suatu organisasi secara sistematis dan aktif.

c. Cara perusahaan menyimpan, mengatur dan mengakses informasi internal dan Eksternal.

d. Mencerminkan sistem yang terintegrasi menyeluruh dalam akumulasi, integrasi, manipulasi, dan akses data di lintas beberapa organisasi.
2. Menurut Achmad Djunaedi dalam bahan kuliah MIP UGM (2014) bahwa manajemen pengetahuan (knowledge management) adalah manajemen terkait pengetahuan yang penting secara eksplisit dan sistematis dan prosesnya terkait penciptaan, pengorganisasian, penyebaran, penggunaan dan eksploitasi pengetahuan.

\section{B. Jenis Penerapan Knowledge Management}

Perbedaan yang paling signifikan di antara jenis knowledge ialah tacit versus explicit (Nonaka dan Takeuchi, 1995). Di dalam organisasi explicit knowledge tidak menjadi masalah karena mudah didokumentasikan, diarsipkan, dan diberi kode. Di lain pihak, tacit knowledge merupakan suatu tantangan tersendiri karena pengetahuan sering kali dirasakan sangat berharga untuk dibagikan dan digunakan dengan cara yang tepat. Pemahaman akan perbedaan kedua jenis knowledge ini sangatlah penting, dan yang perlu diperhatikan juga adalah aplikasinya dengan cara yang berbeda untuk memindahkan jenis knowledge yang berbeda.

Berdasarkan paparan di atas dapat dideskripsikan bahwa ada 2 jenis pengetahuan yaitu:

1. Pengetahuan Eksplisit Jenis pengetahuan ini dapat diproses dengan sistem informasi dapat dikodifikasikan dan dicatat, dapat diarsipkan dan dilindungi. Contoh: manual, buku, laporan, dokumen, surat, file-file elektronik.

2. Pengetahuan Tacit Jenis pengetahuan ini ada di "kepala orang", tidak diwujudkan atau didokumentasikan. Contoh: gagasan, persepsi, cara berpikir, wawasan, keahlian/kemahiran.

Pengetahuan eksplisit dan tacit saling bertautan dalam proses KM sehingga yang 
menjadi kunci utama dalam knowledge management adalah berbagi pengetahuan yang ada (knowing what you know) dan pengetahuan untuk inovasi (creating and converting).

\section{Pengungkit Knowledge Management}

Berhasil atau tidaknya suatu organisasi dalam menjalankan kinerjanya, harus berpedoman kepada ke 7 pengungkit di bawah ini:

1. Pengetahuan tentang Pelanggan: merupakan pengetahuan yang paling penting.

2. Pengetahuan (yang ditanam) dalam produk: memberi 'kecerdasan' sebagai nilai tambah.

3. Pengetahuan (yang ditanam) dalam People: tapi orang bisa pergi.

4. Pengetahuan (yang ditanam) dalam proses: know-how bila diperlukan.

5. Memory Organisasi: apakah kita tahu apa yang kita ketahui?

6. Pengetahuan dalam hubungan: kekayaan dan kedalaman.

7. Aset Pengetahuan: modal intelektual.

\section{Strategi Implementasi KM}

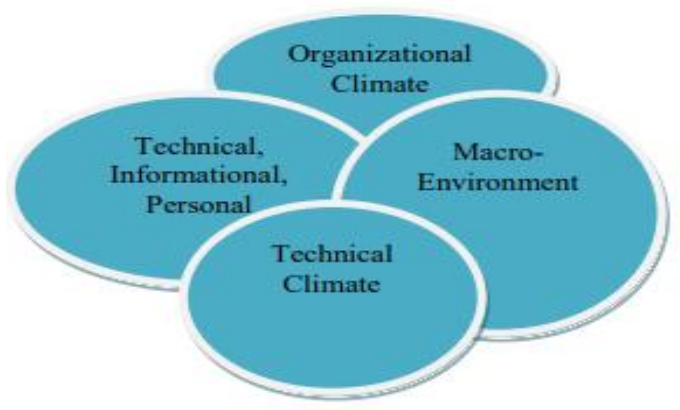

Gambar 1. Strategi Implementasi KM

Persaingan antar organisasi semakin
ketat karena berlomba-lomba untuk memberikan kualitas dan kuantitas terbaik terhadap produk (barang atau jasa) untuk user. Organaisasi atau lembaga informasi ditantang untuk mempertahankan eksistensinya melakukan berbagai inovasi atau terobosan baru untuk menciptakan sistem yang lebik efektif dan efisien, serta memiliki daya saing yang tinggi. Untuk itu setiap organisasi atau perpustakaan harus mengetahui strategi knowledge management sebagai berikut:

1. Macro Environment Perpustakaan dapat melihat faktor-faktor eksternal seperti globalisasi dan teknologi.

2. Organizational Climate Lingkungan organisasi perpustakaan mampu melihat strktur formal, tujuan yang akan dicapai serta budaya di lingkungan perpustakaan itu sendiri.

3. Technical Climate Infrastuktur perpustakaan sangat mempengaruhi perpustakaan untuk berubah dan melihat kebutuhan pengguna atau user.

4. Technical, Informational, Personal Memberikan motivasi kepada bawahan sangat dibutuhkan sehingga SDM dalam menjalankan tugasnya mampu berkompetisi dengan organisasi lain.

\section{E. Faktor Kesuksesan Organisasi Dalam Implementasi KM}

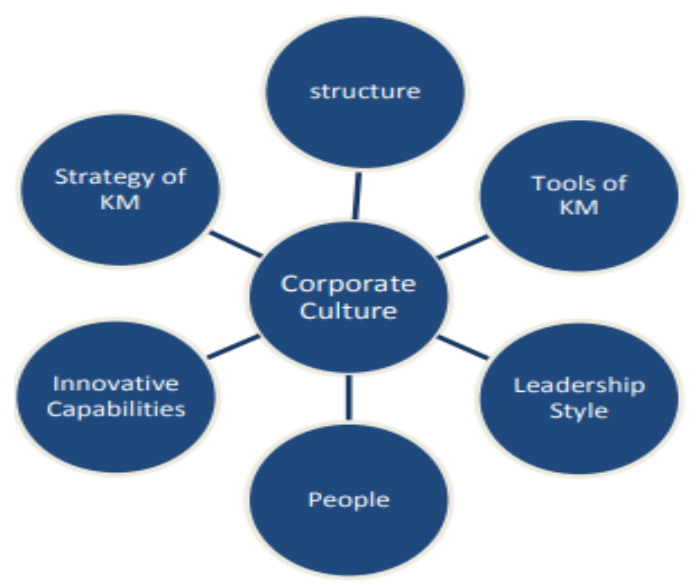

Gambar 2. Faktor Kesuksesan Implementasi KM 
Satu lembaga informasi seperti perpustakaan, untuk meningkatkan kinerja dan produktivitasnya harus mempelajari dan memahami faktor-faktor apa saja yang dapat mendukung suksesnya sebuah lembaga informasi. Di bawah ini ada beberapa faktor kesuksesan lembaga informasi dalam knowledge management yaitu:

1. Corporate Culture Perpustakaan harus mampu memberikan atau meningkatkan budaya penyebaran informasi seperti budaya membaca.

2. Structure Struktur yang digunakan perpustakaan untuk mentransfer pengetahuan kepada pengguna. Perpustakaan harus mampu mendesain sistem yang digunakan sebagai penyalur pengetahuan kepada user.

3. Tools of KM Teknologi adalah suatu alat (tool) yang digunakan dalam mengembangkan sistem perpustakaan. Dukungan infrastruktur yang kuat dalam penyebaran informasi pada orang yang tepat dan waktu yang tepat pula.

4. Leadership Style Keberhasilan KM didukung peran pemimpin dalam membangun visi yang kuat dengan menggalang dan mengarahkan partisipasi semua anggota organisasi dalam mewujudkan visinya.

5. People Baik berupa tacit knowledge ataupun explicit knowledge yang mampu disharing/transfer dalam institusi atau organisasi.

6. Innovative Capabilities Kemampuan berinovasi dan belajar untuk setiap individu sehingga muncul ide-ide, inovasi dan pengetahuan baru, yang menjadi komoditas utama dalam KM.

7. Strategy of KM Strategi atau terobosan baru perpustakaan dalam menciptakan pengetahuan yang baru sehingga perpustakaan tetap eksis dalam menjalankan fungsinya.

\section{F. Perpustakaan Sekolah}

Sebelum mengulas tentang perpustakaan sekolah, terlebih dahulu penulis akan mengemukakan pengertian perpustakaan secara umum. Pengertian perpustakaan dapat ditinjau dari dua segi, yaitu :

1. Pengertian perpustkaan menurut bahasa

a. Istilah "perpustakaan" dalam bahasa Indonesia dibentuk dari kata dasar pustaka ditambah awalan "per" dan akhiran "an". Menurut Kamus Umum Bahasa Indonesia (1988) perpustakaan diartikan sebagai "kumpulan bukubuku (bahan bacaan, dsb).

b. Menurut Kamus Lengkap Praktis Inggris Indonesia, perpustakaan dalam bahasa Inggris disebut dengan "Library"

2. Pengertian Perpustakan menurut istilah

a. Perpustakaan adalah suatu ruangan, bagian dari gedung atau bangunan, atau gedung itu sendiri, yang berisi buku-buku koleksi, yang disusun dan diatur sedemikian rupa sehingga mudah dicari dan dipergunakan apabila sewaktu-waktu diperlukan untuk dibaca (Sutarno, 2003).

b. Menurut Darmono

Perpustakaan sebagai salah satu unit kerja yang berupa tempat untuk mengumpulkan, menyimpan, mengelola, dan mengatur koleksi bahan pustaka secara sistematis unruk digunakan oleh pemakai sebagai sumber informasi sekaligus sebagai sarana belajar yang menyenangkan.

c. Menurut Ibrahim Bafadal, Perpustakaan adalah suatu unit kerja dari suatu badan atau lembaga tertentu yang mengelola bahan-bahan pustaka, baik berupa buku-buku 
maupun bukan berupa buku (non book material) yang diatur secara sistematis menurut aturan tertentu sehingga dapat digunakan sebagai sumber informasi oleh setiap pemakai.

Dari beberapa pengertian di atas dapat ditarik suatu kesimpulan pengertian perpustakaan secara umum adalah suatu unit kerja yang berupa tempat mengumpulkan, menyimpan, dan memelihara koleksi pustaka baik buku ataupun bavaan lainnya yang diatur, diorganisasikan dan diadministrasikan dengan cara tertentu untuk memberi kemudahan dan digunakan secara kontinu oleh pemakainya sebagai informasi.

a. Adapun beberapa pengertian

perpustakaan sekolah, sebagai berikut :

Menurut Carter V. Good sebagaimana yang dikutip oleh Ibrahim Bafadal memberikan definisi perpustakaan sekolah sebahai koleksi yang diorganisasikan di dalam suatu ruang agar dapat digunakan oleh murid-murid dan guru-guru, yang dalam penyelenggaraannya diperlukan seorang pustakawan yang bisa diambil dari salah seorang guru.

b. Perpustakaan sekolah merupakan perpustakaan yang berada di lingkungan sekolah, bertanggung jawab kepada kepala sekolah dan bertugas untuk melayani sivitas akademika sekolah tersebut. (Surochman, 2007).

Dari beberapa pengertian mengenai perpustakaan sekolah dapat disimpulkan bahwa perpustakaan sekolah adalah suatu unit kerja sebuah lembaga pendidikan yang brupa tempat untuk mengumpulkan, menyimpan, mengelola, dan mengatur koleksi bahan pustaka baik yang tertulis, tercetak, maupun grafis lainya, yang diatur dan diorganisasikan secara sistematis untuk dipergunakan secara berkesinambungan sehungga dapat membantu murid-murid dan guru dalam proses belajar mengajar.

\section{G. Analisis SWOT}

Perpustakaan Sekolah dapat dikaji dengan analisis SWOT seperti apakah yang menjadi sumber kekuatan, potensi dan bagaimana menggunakannya, apa saja kelemahannya, bagaimana mengatasi serta memecahkannya, adakah kesempatan, peluang yang dimiliki dan bagaimana memanfaatkannya, apakah perpustakaan menghadapi tantangan atau ancaman dan bagaimana caranya untuk mengatasinya. Sutarno NS (2006) mengatakan bahwa kekuatan dan kelemahan berada di dalam internal organisasi perpustakaan sedangkan kesempatan dan ancaman atau tantangan berada di luar perpustakaan.

\section{H. Analisis Strategi Analis is SWOT}

\section{Strenghs (kekuatan)}

Kekuatan dan potensi perpustakaan adalah semua sumber dan kekayaan (aset) yang dimiliki perpustakaan, untuk sepenuhnya dipergunakan dan diberdayakan secara optimal.

2. Weakness (kelemahan)

Kelemahan perpustakaan adalah suatu kondisi di mana sebuah perpustakaan tidak atau kurang dapat berfungsi sebagaimana mestinya. Kelemahan internal adalah kelemahan yang berada di dalam perpustakaan

3. Opportunity (kesempatan atau peluang)

Kesempatan atau peluang yang dimiliki perpustakaan untuk dapat melakukan halhal yang berguna

4. Threats (tantangan atau ancaman) 
Ancaman yang dihadapi oleh perpustakaan sebagai kelemahan eksternal perpustakaan

Tabel 1. Analisis SWOT

\begin{tabular}{|c|c|}
\hline Strenghs (kekuatan) & Weakness (kelemahan) \\
\hline $\begin{array}{l}\text { - Sumber dava manusia } \\
\text { - Koleksi bahan pustaka } \\
\text { - Sarana dan prasarana } \\
\text { - Pengunjung } \\
\text { - Anggota dan masvarakat pemakai } \\
\text { - Lingkungan perpustakaan } \\
\text { - Mitra keria } \\
\text { - Anggaran }\end{array}$ & $\begin{array}{l}\text { - Sumber daya perpustakaan } \\
\text { - Administrasi } \\
\text { - Manajemen }\end{array}$ \\
\hline Opportunity (kesempatan atau peluang) & Threats (tantangan atau ancaman) \\
\hline $\begin{array}{l}\text { - Perkembangan informasi dan ilmu } \\
\text { pengetahuan } \\
\text { - Teknologi Informasi } \\
\text { - Perkembangan bidang pendidikan } \\
\text { - Kebiiakan pemerintah di bidang } \\
\text { perpustakaan } \\
\text { - Persaingan perpustakaan }\end{array}$ & $\begin{array}{l}\text { - Adanva iarak atau gab memisahkan } \\
\text { antara perpustakaan dan masvarakat } \\
\text { - Adanva keterbatasan akses informasi dan } \\
\text { komunikasi } \\
\text { - Kurangnva sosialisasi } \\
\text { - Respon dan perhatian masvarakat relatif } \\
\text { rendah } \\
\text { - Persepsi yang keliru dan tidak lengkap } \\
\text { tentang perpustakaan } \\
\text { - Tingkat kesibukan } \\
\text { - Kebutuhan }\end{array}$ \\
\hline
\end{tabular}

\section{METODE PENELITIAN}

Penelitian ini menggunakan metode penelitian deskriptif dengan pendekatan kualitatif. Penelitian deskriptif ini juga disebut dengan feasibility study yang bermaksud untuk memperoleh data awal (Soerjono. S. 1974:29). Penelitian deskriptif merupakan mempelajari masalah-masalah dalam masyarakat serta tatacara yang berlaku dalam masyarakat serta situasi-situasi tertentu, termasuk tentang hubungan, kegiatan-kegiatan, sikap-sikap, pandanganpandangan, serta proses-proses yang sedang berlangsung dan pengaruh-pengaruh dari suatu fenomena. Penelitian dengan metode deskriptif biasanya dilakukan melalui observasi, wawancara, dan studi kasus untuk menggambarkan perilaku daripada menggunakan data yang bisa dianalisis secara statistik.

Teknik pengumpulan data dalam penelitian menggunakan beberapa instrumen atau alat yang dapat dipakai sebagai pengumpul data agar data lebih akurat. Teknik Pengumpulan data merupakan "langkah yang paling strategis dalam penelitian, karena tujuan utama dari penelitian adalah mendapatkan data". Sugiyono (2011: 224). Teknik pengumpulan data yang di gunakan dalam penelitian ini melalui :

1. Studi Literatur

2. Observasi

3. Interview

4. Dokumentasi

\section{ANALISIS DATA}

Teknik analisis data yang digunakan dalam penelitian ini adalah menggunakan teknik analisis SWOT dengan pendekatan kualitatif, yang terdiri dari Strenghts, Weakness, Opportunities dan Threaths. Analisis SWOT bertujuan untuk memaksimalkan kekuatan (strengths) dan peluang (opportunities), namun dapat meminimalkan kelemahan (weakness) dan ancaman (threaths).

\section{HASIL DAN PEMBAHASAN}

1. Knowledge Management dalam Perpustakaan Sekolah Menengah Atas. Perpustakaan sekolah sebagai perpustakaan Pendidikan akan tetap eksis memainkan peranannya dalam kehidupan suatu sekolah. Sebagai pusat informasi, perpustakaan memperoleh tempat sentral karena perpustakaan melayani semua fungsi unit di sekolah. Perpustakaan merupakan instrument dinamis pendidikan dan pelayanan yang diberikan akan mempengaruhi keseluruhan program sekolah. Keseluruhan aktivitas ini berkaitan dan diperlukan untuk perkembangan ilmu pengetahuan. Dalam melakukan kegiatannya tersebut. 
Kemajuan pesat TIK dan budaya materialis termasuk didalamnya fasilitas internet dapat mempercepat siklus pengetahuan lintas dan multi disiplin yang akan digunakan oleh siswa/siswi untuk mendapatkan informasi. Pembelajaran secara kolaboratif juga perlu digalakkan. Dengan cara inilah, siswa/siswivyang mencernakan sumber informasi yang berbeda-beda bisa saling berbagi pengetahuan dan memperkaya diri. Menanggapi perkembangan tersebut, perpustakaan sekolah mau tidak mau harus berubah, kalau tidak akan ditinggalkan oleh penggunanya. Perpustakaan sekolah harus memainkan peranan aktif dan penting dalam siklus pengetahuan syaitu memperluas cakupan kegiatannya dari manajemen informasi menjadi manajemen pengetahuan dan lebih berfokus pada penawaran keahlian untuk memperlengkapi pengguna agar dapat belajar terus-menerus, dari pada penawaran akses informasi.

Ada beberapa hal yang dapat dilakukan perpustakaan SMA yaitu:

a. Manajemen Pengetahuan

Mulai dari penciptaan, perekaman dan organisasi, penyebaran, akses dan pengunaan, dan dilanjutkan dengan penciptaan kembali pengetahuan, dan seterusnya. Selama ini perpustakaan lebih banyak berfokus pada penyediaan akses dan penyebaran informasi. Disamping itu, perpustakaan selama ini lebih memperhatikan pengetahuan yang sudah terekam di luar pikiran penciptanya. Padahal banyak pengetahuan yang masih dalam kepala orang (dan belum pernah direkam dalam sumber-sumber informasi yang umumnya dikelola oleh perpustakaan selama ini) b. Menjadi Mitra Bagi Pengguna

Pengguna perpustakaan perguruan tinggi adalah sivitas akademika yaitu orang-orang yang tugasnya mengajar, belajar dan melakukan penelitian. Untuk itu mereka harus membuat rancangan penelitian, pembelajaran suatu matakuliah, membuat bahan ajar, memberikan pada mahasiswa, mengembangkan alat penelitian, mengumpulkan data, menulis laporan penelitian, belajar membuat tugas kuliah, mencari sponsor penelitian, sponsor kuliah. Menjadi Mitra berarti pustakawan harus turut mengambil bagian yang penting dalam kegiatan tesebut. Dengan demikian, pustakawan bukan hanya sekedar mencarikan informasi dan memberi bantuan teknis tetapi menjadi mitra demi peningkatan mutu kegiatan yang bersangkutan dan juga mutu perguruan tinggi.

c. Melayani Individu atau Kelompok Sebagai Anggota Jaringan

Kemajuan TIK memudahkan dan mendorong terjadinya kolaborasi diantara orangorang dan kelompokkelompok yang tidak saling kenal dan dipisahkan oleh jarak dan waktu. Karena itu, supaya efektif dan efisien, perpustakaan harus memandang pengguna dan membantu mereka melakukan pengelolaan pengetahuannya dalam konteks jaringan. Konsekuensinya, perpustakaan perlu menyediakan fasilitas untuk mereka terhubung, berbagi pengetahuan dan berkolaborasi, dengan orang-orang di dalam dan luar kelompoknya

d. Fasilitas Manajemen Pengetahuan Dibandingkan dengan internet, fasilitas perpustakaan perguruan tinggi yang ada saat ini masih jauh 
dari memadai untuk menghadapi tantangan tersebut diatas. Dengan fasilitas yang demikian, perpustakaan tidak bisa berperan penting. Perpustakaan bahkan akan cenderung diabaikan.

2. Dampak KM Bagi Pimpinan Perpustakaan

Untuk memahami semua teori-teori diatas dibutuhkan seorang pimpinan yang mampu untuk melalukannya. Perpustakaan Sekolah akan berbenah diri untuk mengimplementasikan KM dalam kegiatan operasionalnya sehingga dapat meningkatkan kinerja dan produktivitasnya sebagai lembaga informasi. Hal ini juga akan berdampak positif bagi seorang pimpinan di perpustakaan seperti :

1. Memimpin dengan cara yang kreatif dan mendalam

2. Mampu melihat situasi dengan jelas dan bergerak maju menciptakan solusi

3. Mampu membangun koneksi yang bermakna untuk meningkatkan jejaring dan pendukungnya

4. Pemimpin yang sukses melihat keterlibatan dalam kepemilikan sebagai peluang sekaligus resiko, adaptif dan kolaboratif

5. Mampu mendefinisikan masa depan

6. Mampu mengidentifikasi masalah secara terbuka (dan satukan kekuatan untuk menyelesaikannya)

7. Mendukung initiative-taking \& kepemimpinan di setiap level

8. Mampu menyelesaikan konflik

9. Mampu mengelola perubahan

10. Mampu meningkatkan komunikasi dan mendorong orang lain melakukannya.

Dari implementasi KM tersebut di atas diharapkan Perpustakaan Sekolah untuk masa depan dapat berkompetisi dengan lembaga informasi lain sehingga mampu menghadapi tantangan global. Pengelolaan organisasi perpustakaan di era global saat ini dan mendatang jelas berbeda dengan era sebelumnya. Pada era global, pengelolaan organisasi menuntut ketanggapan dan kemampuan adaptif dari para pengelola perpustakaan. Hal ini disebabkan begitu banyak perubahan yang terjadi dari lingkungan eksternal dan internal organisasi perpustakaan.

\section{KESIMPULAN}

Berdasarkan paparan di atas dapat disimpulkan bahwa:

1. Dengan membuat analisis SWOT dan dengan tuntutan pengguna yang semakin meningkat, bahkan adanya ancaman mulai terpinggirkannya perpustakaan oleh Internet, dibutuhkan alat yang tepat bagi perpustakaan sekolah untuk tetap dapat berkompetisi. Manajemen pengetahuan merupakan salah satu alat yang dapat menolong perpustakaan dalam kondisi ini.

2. Knowledge Management menawarkan suatu peluang bagi pimpinan dan petugas perpustakaan untuk menjadikan diri mereka relevan terhadap tuntutan zaman. Walaupun beragam teori Knowledge Management, tetapi konsep yang ditawarkannya dapat dijadikan sebagai titik tolak bagi pimpinan dan petugas perpustakaan untuk lebih berperan secara substansial dalam menyediakan seluruh pelayanan informasi dan pengetahuan bagi pengguna perpustakaan.

3. Implementasi Knowledge Management di Perpustakaan Sekolah masih memerlukan penyempurnaan khususnya dalam hal strategi, culture, pengembangan sumber daya manusia dan kepemimpinan.

Dengan diterapkannya KM diharapkan :

1. Hadir seorang pimpinan Perpustakaan Sekolah yang mempunyai kemampuan untuk mengelola perpustakaan dan menjadi fasilitator KM 
2. Pustakawan Perpustakaan Sekolah harus segera mengambil prakarsa untuk mengeksplorasi potensi informasi dan pengetahuan yang ada di perpustakaan serta kemampuan untuk menulis ilmiah.

3. Dukungan penuh dari pengambil kebijakan di Sekolah

\section{DAFTAR PUSTAKA}

Awad, Elias M. Ghaziri, Hasan M. 2003.

K Management ,New Jersey Person Education. Inc,

Bafadal Ibrahim. 2009. Pengelolaan Perpustakaan Sekolah. Jakarta: Bumi Aksara

Calzada, Javier and Miguel Angel Marzal. 2013. Library and Information Professionals as Knowledge Engagement Specialist: theories, competencies and current educational possibilities in accredited. Information Research: an international electronic journal Vol. 18 No. 3 September 2013.

Calzada, Javier and Miguel Angel Marzal. 2013. Library and Information Professionals as Knowledge Engagement Specialist: theories, competencies and current educational possibilities in accredited. Information Research: an international electronic journal Vol. 18 No. 3 September 2013.

Djunaedi, Achmad. 2014. Bahan Kuliah Pengelolaan Informasi dan Dokumentasi MIP 2013. Yogyakarta : Sekolah Pascasarjana Minat Studi Manajemen Informasi dan Perpustakaan

Darmono. 2001. Manajemen dan Tata Kerja Perpustakaan Sekolah. Jakarta : Gramedia Widia Sarana
Forcadell, Francisco J. and Fatma Guadamilles. 2002. A Case study on implementation of a knowledge management strategy oriented to innovation. J Knowledge and Process Management Vol. 9 No. 3 2002; 16217.

Galagan, P. 1997. Smart Companies (knowledge management). Training and Development, 51 (12), 20-25.

Hadagali, Gururaj S., dkk. 2012. Knowledge Management in Libraries: a new perspective for the library professionals in the competitive world. International Journal of Information Dissemination and Technology Vol. 2 No.1 2012.

Hasibuan, Ahmad Syarifuddin. 2011. Penerapan Manajemen Pengetahuan Perpustakaan Perguruan Tinggi, pdf, http://syarifuddin46.blogstudent.mb.ip b.ac.id/2011/10/03/39/.

Diakses tanggal 14 Mei 2014.

Kimble, Chris. 2013. Knowledge Management, Codification and Tacit Knowledge. Information Research: an international electronic journal Vol. 18 No. 2 June, 2013.

Komaruddin, Yooke Tjuparman S. 2008. Kepemimpinan Perpustakaan PT Pada Era TIK, ppt, Seminar Ilmiah dan Workshop Digital Library for Resource Sharing, Bogor : FPPPTI 